$\xi=-1$

\title{
Make or Buy Decision Making with the Consideration of Inventory Cost
}

\author{
Jirarat Teeravaraprug ${ }^{1 *}$, Tarathorn Potcharathitikull ${ }^{2}$ \\ ${ }^{1}$ Department of Industrial Engineering, Thammasat University, Pathumthani, THAILAND \\ ${ }^{2}$ College of Industrial Technology, King Mongkut's University of Technology North Bangkok, Bangkok, THAILAND \\ *Email: tjirarat@engr.tu.ac.th
}

\begin{abstract}
Make or buy decision making has recently received substantial theoretical and empirical attention. This paper integrates inventory cost in make or buy decision making. Many practitioners think that inventory cost is low when comparing with other types of costs. Therefore inventory cost seems to be neglect. This paper proposed two mathematical models of total costs in the cases of make and buy with the consideration of inventory costs. Based on the numerical example, it shows that the decision making may be changed with and without considering inventory costs. Further, considering variations of demand and purchase lead time, it is found that high demand variation tends to use buy option whereas high purchase lead time variation tends to use make option.
\end{abstract}

Keywords: Make or buy, Outsourcing, Inventory, Mathematical models

\section{Introduction}

Academics and practitioners have paid attentions in outsourcing issue for the past years. The issue along outsourcing - is called as make or buy problem. It is the problem of which activities a manufacturing firm should complete for itself and for which it should rely on outside suppliers. It is clear that make or buy decision has to incorporate strategic considerations. Many researches deal with strategic and organizational issues such as core competence and organizational flexibility (e.g. [1]-[4]).

Conventional wisdom suggests that the sourcing decision (i.e., producing in-house or purchasing from an outside supplier) may simply be a matter of choosing the least cost alternative by comparing internal production costs with the prices charged by the independent suppliers. Coarse [5] recognizes that it is not simply the price being charged in the market that needs to be taken into account, but all the costs of acquiring the commodity or process. It is found from previous studies that outsourcing decision depends some key factors such as scale economies, capacity pooling, market entry, product substitution, demand risk, etc. Therefore, a trend appears to be towards reducing the scope of internal activities and relying to a greater extent on suppliers.

A major issue in make or buy is to distinguish between strategic and non-strategic parts. Generally strategic parts would be produced in-house for competitive reasons. On the other hand, the items considered standard items would generally be purchased. Other strategic issues in make or buy include the cost of the updated technology required to continue manufacturing the part inhouse, asset utilization, whether outsourcing would reduce significantly the barriers to entry, whether it would reduce the company's leverage in the supply chain, and whether it would hinder or help time to market for new products [6]. Walker and Weber [7] describe other strategic issues such as uncertainty in technology and volume and competition among suppliers in make or buy decision. Burt et al. [8] considers financial implications in make or buy decision making. Recent publications using traditional cost accounting for make or buy decision include in [9]. Anderson and Katz [10] and Balakrishnan and Cheng [6] include capacity constraints in make or buy decision making.

This paper focuses on the Make or Buy issue with the consideration of inventory cost. The considered costs in this paper include manufacturing cost and purchase cost with fixed and variable cost types, inventory costs when considered safety stocks.

\section{Notations}

Notations are shown in Table 1.

\section{Mathematical model}

When considering make or buy, people normally think about cost. They generally compare unit production cost and unit purchase cost. In economics, production cost includes fixed cost and variable cost. A fixed cost is a cost that does not change with an increase or decrease in the amount of goods or services produced. A fixed cost is an operating expense of a business that cannot be avoided regardless of level of production. Whether a firm produces or not, it must pay its fixed cost. Variable cost is a cost that changes in proportion with production output. Variable cost increases or decrease depending on level of production. The variable cost of production is a constant amount per unit produced. Therefore, considering only unit production cost and unit purchase cost may not be a good means. This paper considers those two types of costs-fixed and variable costs. Further, costs of production planning and control, production ordering, and inventory are consid- 
ered in the make case. Costs of purchase, ordering and also inventory are considered in the buy case. Inventory cost that is consid Table 1: Notations

\begin{tabular}{|l|l|}
\hline Symbols & Meanings \\
\hline$T C_{M}$ & Total cost of make case \\
\hline$T C_{B}$ & Total cost of buy case \\
\hline$F P C$ & Total fixed production cost \\
\hline$V P C$ & Total variable production cost \\
\hline$v$ & Unit variable production cost \\
\hline$P R$ & Unit price of item purchased from supplier \\
\hline$P P C$ & Total production planning and control cost \\
\hline$P C$ & Production planning and control cost per time \\
\hline$T O C_{M}$ & Total production ordering cost \\
\hline$O C_{M}$ & Production ordering cost per time \\
\hline$T O C_{B}$ & Total procurement and ordering cost \\
\hline$O C_{B}$ & Procurement and ordering cost per time \\
\hline$T C C_{M}$ & Total carrying cost in the case of make \\
\hline$T C C_{B}$ & Total carrying cost in the case of buy \\
\hline$S S_{M}$ & Number of safety stock in the case of make \\
\hline$S S_{B}$ & Number of safety stock in the case of buy \\
\hline$I_{M}$ & Total annual inventory in make case \\
\hline$I_{B}$ & Total annual inventory in buy case \\
\hline$L_{M}$ & Production lot size \\
\hline$L_{B}$ & Ordering lot size \\
\hline$p$ & Production rate (unit per period) \\
\hline$D$ & Annual demand \\
\hline$h$ & Annual holding cost per unit \\
\hline & \\
\hline
\end{tabular}

ered in this paper is carrying cost. Safety stocks in both cases are included in the consideration.

\subsection{Make case}

The total costs in the make case include fixed production cost variable production cost, production planning and control, production ordering cost, and carrying cost. Example of fixed production cost include factory rent, factory depreciation, machine depreciation, monthly salary, insurance, property taxes, interest expense and etc. Example of variable production cost includes raw materials cost, utility cost, direct labor cost, and etc. Production planning is the planning of production and manufacturing modules in a company or industry. It utilizes the resource allocation of activities of employees, materials, and production capacity. Production control is the activity of monitoring and controlling any particular production or operation. The cost of production planning and control is the cost associated with those activities. The production ordering cost is the cost associated with production ordering and scheduling. Sometimes this cost is included in the cost of production planning and control. Normally, the cost of planning and control per time depends on the number of time to plan and control. In this paper, the number of time to plan and control is assumed to depend on production lot size. So that when the lot size is large, the number of time to plan and control is low. Thus the cost of planning and control is low. Contrarily, when the lot size is small, the number of time to plan and control is high. The cost of planning and control is high. Similar to the cost of planning and control, the total production ordering cost depends on the number of time to order. The number of time to order is assumed to depend on production lot size. When the lot size is large, the number of time to order is low. Thus the ordering cost is low. Contrarily, when the lot size is small, the number of time to order is high. The ordering cost is high.
The reason of those is, normally some activities are combined among products or items. The costs already incur. If there is an activity of the product or item, the cost is allocated to that product or item. The last one, carrying cost, is the cost of holding inventories. Inventories include safety stock and expected holding items. Replenishment of items is in the case of non-instantaneous replenishment. The costs associated to the Make case are shown in. (1$5)$.

$T C_{M}=F P C+V P C+P P C+T O C_{M}+T C C_{M}$

where

$V P C=v \cdot D$,

$P P C=\frac{P C \cdot D}{L_{M}}$,

$T O C_{M}=\frac{O C_{M} \cdot D}{L_{M}}$

and

$T C C_{M}=h \cdot\left(S S_{M}+I_{M}\right)$.

Equation (1) shows the total costs of make case equal to the summation of all associated components. Equations (2-6) shows the means to calculate each component. As discussed before, FPC is the total fixed production cost normally in yearly basis. VPC depends on the number of production. Equation (2) shows that $V P C$ is calculated by the product of $v$ and annual demand. $P P C$ is the product of the number of time to plan and control and its cost per time. Similarly, $T O C_{M}$ is the product of the number of time to order and its cost per time. $T C C_{M}$ is the product of the average holding number and the annual holding cost per unit. The average holding unit comprises safety stock and average inventory. In the make case, production lead time is adjusted by the company itself. So, safety stock can be calculated as shown in. (6).

$s s_{M}=z_{\alpha} \cdot \sqrt{E(L) \sigma_{D}^{2}}$,

where $\alpha$ is the service level and $z_{\alpha}$ is the inverse distribution function of a standard normal distribution with cumulative probability $\alpha$. It is normal to assume that $\alpha$ equals $95 \%$ service level and then $z_{\alpha}$ equals 1.65. $E(L)$ is the mean of lead time where as $\sigma_{D}$ is the standard deviation of demand. The average inventory in this case can be calculated as shown in (7).

$I_{M}=L_{M}\left(1-\frac{D}{p}\right)$

\subsection{Buy case}

The main cost in buy case is the purchase cost including transportation cost. In this research, not only purchase cost is considered, but procurement and ordering costs, and carrying cost as well. Procurement and ordering costs normally depend on the number of ordering times and procurement and ordering costs per time is constant. Carrying cost is the cost of holding inventories including safety stock and expected holding items. Since make case can control production and replenishment by the company itself. Therefore, the number of safety stock in buy case should higher than that in make case. Moreover, the replenishment of buy case is in the case of instantaneous case. The costs associated to the Buy case are shown in (8-10). 
$T C_{B}=P R \cdot D+T O C_{B}+T C C_{B}$

where

Table 2: Costs of make and buy cases when the standard deviation of demand is changed

\begin{tabular}{|c|c|c|c|c|c|c|c|c|c|c|c|}
\hline \multirow{2}{*}{$\sigma_{D}$} & \multicolumn{6}{|c|}{ MAKE } & \multicolumn{4}{|c|}{ BUY } & \multirow{2}{*}{ Decision } \\
\hline & $F P C$ & $V P C$ & $P P C$ & $T O C_{M}$ & $T C C_{M}$ & Total & $P R * D$ & $T O C_{B}$ & $T C C_{B}$ & Total & \\
\hline 0 & 10000 & 20400 & 240 & 240 & 0.00 & 30880.00 & 30000 & 600 & 505.00 & 31105.00 & MAKE \\
\hline 5 & 10000 & 20400 & 240 & 240 & 36.90 & 30916.90 & 30000 & 600 & 505.01 & 31105.01 & MAKE \\
\hline 10 & 10000 & 20400 & 240 & 240 & 73.79 & 30953.79 & 30000 & 600 & 505.03 & 31105.03 & MAKE \\
\hline 15 & 10000 & 20400 & 240 & 240 & 110.69 & 30990.69 & 30000 & 600 & 505.07 & 31105.07 & MAKE \\
\hline 20 & 10000 & 20400 & 240 & 240 & 147.58 & 31027.58 & 30000 & 600 & 505.13 & 31105.13 & MAKE \\
\hline 25 & 10000 & 20400 & 240 & 240 & 184.48 & 31064.48 & 30000 & 600 & 505.21 & 31105.21 & MAKE \\
\hline 30 & 10000 & 20400 & 240 & 240 & 221.37 & 31101.37 & 30000 & 600 & 505.30 & 31105.30 & MAKE \\
\hline 35 & 10000 & 20400 & 240 & 240 & 258.27 & 31138.27 & 30000 & 600 & 505.40 & 31105.40 & BUY \\
\hline 40 & 10000 & 20400 & 240 & 240 & 295.16 & 31175.16 & 30000 & 600 & 505.53 & 31105.53 & BUY \\
\hline 45 & 10000 & 20400 & 240 & 240 & 332.06 & 31212.06 & 30000 & 600 & 505.67 & 31105.67 & BUY \\
\hline 50 & 10000 & 20400 & 240 & 240 & 368.95 & 31248.95 & 30000 & 600 & 505.82 & 31105.82 & BUY \\
\hline 55 & 10000 & 20400 & 240 & 240 & 405.85 & 31285.85 & 30000 & 600 & 506.00 & 31106.00 & BUY \\
\hline 60 & 10000 & 20400 & 240 & 240 & 442.74 & 31322.74 & 30000 & 600 & 506.19 & 31106.19 & BUY \\
\hline 65 & 10000 & 20400 & 240 & 240 & 479.64 & 31359.64 & 30000 & 600 & 506.39 & 31106.39 & BUY \\
\hline 70 & 10000 & 20400 & 240 & 240 & 516.53 & 31396.53 & 30000 & 600 & 506.61 & 31106.61 & BUY \\
\hline 75 & 10000 & 20400 & 240 & 240 & 553.43 & 31433.43 & 30000 & 600 & 506.85 & 31106.85 & BUY \\
\hline 80 & 10000 & 20400 & 240 & 240 & 590.32 & 31470.32 & 30000 & 600 & 507.11 & 31107.11 & BUY \\
\hline 85 & 10000 & 20400 & 240 & 240 & 627.22 & 31507.22 & 30000 & 600 & 507.38 & 31107.38 & BUY \\
\hline 90 & 10000 & 20400 & 240 & 240 & 664.11 & 31544.11 & 30000 & 600 & 507.67 & 31107.67 & BUY \\
\hline 95 & 10000 & 20400 & 240 & 240 & 701.01 & 31581.01 & 30000 & 600 & 507.97 & 31107.97 & BUY \\
\hline 100 & 10000 & 20400 & 240 & 240 & 737.90 & 31617.90 & 30000 & 600 & 508.29 & 31108.29 & BUY \\
\hline
\end{tabular}

Table 3: Costs of make and buy cases when the standard deviation of purchasing lead time is changed

\begin{tabular}{|c|c|c|c|c|c|c|c|c|c|c|c|}
\hline \multirow[b]{2}{*}{$\sigma_{L}$} & \multicolumn{6}{|c|}{ MAKE } & \multicolumn{4}{|c|}{ BUY } & \multirow{2}{*}{ Decision } \\
\hline & $F P C$ & $V P C$ & $P P C$ & $T O C_{M}$ & $T C C_{M}$ & Total & $P R * D$ & $T O C_{B}$ & $T C C_{B}$ & Total & \\
\hline 0 & 10000 & 20400 & 240 & 240 & 147.58 & 31027.58 & 30000 & 600 & 21.43 & 30621.43 & BUY \\
\hline 0.5 & 10000 & 20400 & 240 & 240 & 147.58 & 31027.58 & 30000 & 600 & 93.29 & 30693.29 & BUY \\
\hline 1 & 10000 & 20400 & 240 & 240 & 147.58 & 31027.58 & 30000 & 600 & 175.40 & 30775.40 & BUY \\
\hline 1.5 & 10000 & 20400 & 240 & 240 & 147.58 & 31027.58 & 30000 & 600 & 257.76 & 30857.76 & BUY \\
\hline 2 & 10000 & 20400 & 240 & 240 & 147.58 & 31027.58 & 30000 & 600 & 340.20 & 30940.20 & BUY \\
\hline 2.5 & 10000 & 20400 & 240 & 240 & 147.58 & 31027.58 & 30000 & 600 & 422.66 & 31022.66 & BUY \\
\hline 3 & 10000 & 20400 & 240 & 240 & 147.58 & 31027.58 & 30000 & 600 & 505.13 & 31105.13 & MAKE \\
\hline 3.5 & 10000 & 20400 & 240 & 240 & 147.58 & 31027.58 & 30000 & 600 & 587.61 & 31187.61 & MAKE \\
\hline 4 & 10000 & 20400 & 240 & 240 & 147.58 & 31027.58 & 30000 & 600 & 670.10 & 31270.10 & MAKE \\
\hline 4.5 & 10000 & 20400 & 240 & 240 & 147.58 & 31027.58 & 30000 & 600 & 752.59 & 31352.59 & MAKE \\
\hline 5 & 10000 & 20400 & 240 & 240 & 147.58 & 31027.58 & 30000 & 600 & 835.08 & 31435.08 & MAKE \\
\hline
\end{tabular}

$T O C_{M}=\frac{O C_{B} \cdot D}{L_{B}}$

and

$T C C_{B}=h \cdot\left(S S_{B}+I_{B}\right)$.
The first term of (8) right hand side is the purchase cost. The second term and (9) is the ordering cost and the means to calculate. The total procurement and ordering cost equals to the product of the number of time to order and its associated cost. The number of time to order equals to $D / L_{B}$. Next and (10) is the total carrying 
cost and the means to calculate. The total carrying cost is the product of the average carrying units and the annual cost per unit. Again, the carrying units include safety stock and inventory. Safety stock can be calculated by (11).

$s s_{B}=z_{\alpha} \cdot \sqrt{E(L) \sigma_{D}^{2}+E(\mathrm{D})^{2} \sigma_{L}^{2}}$,

where $E(D)$ is the mean of time in each unit time period, and $\sigma_{L}$ is the standard deviation of lead time. The average inventory in this case can be calculated as shown in (12).

$I_{B}=L_{B} / 2$

\section{Numerical example}

A company presently produces 6,000 unit of part A per annual to use with the main product. The demand seems to be normally distributed with the mean $=500$ unit per month and the standard deviation $=20$ unit per month. The company is deciding whether the part should be manufactured inside or purchased from a supplier. The fixed production cost is 10,000 dollar per annual whereas the variable production cost per unit is 3.4 dollar per unit. In order to manufacture the part inside, the company needs to pay for the cost of planning and control, and production ordering cost. They are 2 dollar each ordering time. The production lot size is 50 unit and the production rate is 500 unit per month. In the case of purchase the parts from supplier, the cost of purchase per unit is 5 dollar. The procurement and ordering cost is 10 whereas the lot size is 100 units. The mean and standard deviation of ordering lead time are 3 months. Considering only production cost and purchase cost, the total production cost is 30,400 dollar whereas the purchase cost is 30,000 dollar. The company should purchase the part.

By calculating total costs in (1) and (8), it is found that the cost of make case is $31,027.58$ dollar per year whereas the cost of buy case equals to $31,105.13$ dollar per year. The cost of make case is less than that of buy case. Therefore, the company should manufacture the part inside.

Table 2 shows the total costs when the standard deviation of demand is changed. It can be seen that when the demand standard deviation is low, the company should produce inside. Contrarily, when the demand standard deviation is high, the company should purchase the part from a supplier.

Table 3 shows the total costs when the standard deviation of purchasing lead time is changed. It can be seen that when the standard deviation of purchasing lead time is high, the company should not buy the part from a supplier. The company should produce the part inside. When the standard deviation is low, the company should buy the part.

\section{Conclusion}

This paper deals with the make or buy problem with the consideration of inventory cost. Two mathematical models to calculate total costs in the case of make and buy are given. Based on the numerical example, by comparing only production cost and purchase cost is not enough to justify make or buy. Consider only those costs, the company should purchase the parts from the supplier. Using the proposed total costs of make and buy cases, the cost of make case is lower than that of buy case. Therefore, when considering all costs, the company should decide to manufacture inside (or make). Further when the case that the demand is highly varied, the company should decide to buy. When the variation of purchasing lead time is high, the company should decide to produce inside.

\section{Acknowledgement}

The authors gratefully acknowledge the financial support provided by Faculty of Engineering, Thammasat University and Thammasat University.

\section{References}

[1] Prahalad CK \& Hamel G (1990), The core competence of the corporation. Harvard Business Review 68, 79-91.

[2] Porter AM (1991), To buy or not to buy. Purchasing, 20-21.

[3] Venkatesan R. (1992) Strategic souring: to make or not to make, Harvard Business Review 70, 98-107.

[4] Sturgeon TJ (2002), Modular production networks: a new American model of industrial organization. Industrial and Corporate Change 11, 98-107.

[5] Coase RH (1937), The nature of the firm. Economica N.S. 4, 386405.

[6] Balakrishnan J. \& Cheng CH (2005), The theory of constraints and the make or buy decision - an update and review. Journal of Supply Chain Management 41, 40-47.

[7] Walker G \& Weber D (1987), Supplier competition, uncertainty and the make or buy decision. Academy of Management Journal 30, 589-596.

[8] Burt DN, Dobler DW \& Starling S (2003), World Class Supply Management, McGraw Hill, New York, NY.

[9] van Damme DA \& van der Zon FLA (1999), Activity based costing and decision support. The International Journal of Logistics Management $10,72-82$.

[10] Anderson MG \& Katz PB (1998), Strategic sourcing. The International Journal of Logistics Management 9, 1-13. 